\title{
6 \\ Is pricing road transport significantly different to pricing other network infrastructure?
}

\author{
Alex Robson
}

\section{Introduction}

Australian governments have faced a number of challenges implementing significant policy reforms over the past few decades. The road transport sector is one area where reform has proved particularly challenging. Explaining the problems associated with road usage-especially in relation to funding issues, maintenance, road pricing and congestion chargingis not an easy task. In many areas, we already have user charging for the private enjoyment of publicly provided goods (for example, universities, utilities, rail transport and ports), but not generally in relation to roads, outside a few toll corridors and tunnels. Many argue that this situation will need to change to ensure a more efficient allocation of scarce resources and to align supply with demand.

Proponents of user charging argue that it is intended to serve two broad economic purposes. On the demand side, user charges are intended to provide a transparent price signal of the direct opportunity or resource costs of a project to those who derive direct benefits from its provision. The main idea behind such a price signal is that the introduction of a user charge will encourage efficient resource utilisation of a given facility- 
in economic terms, up to the point where marginal benefits equal marginal resource costs. This price signal will have the effect of limiting the possibility that the facility will be over-utilised. The second objective relates to the supply side: appropriately designed user-charging arrangements may provide a signal to the private sector and the government, assisting them to allocate resources efficiently across a range of projects and other uses, so policy objectives can be achieved in a cost-effective manner.

Although price signals can in principle help to achieve these objectives, they are by no means a panacea. Across Australia, we currently have a range of indirect forms of road charging that raise funds, but which on the whole do not provide direct price signals for usage. For passenger vehicles, the main levy is the Commonwealth's fuel excise, which is estimated to amount to a tax of 5.5 cents per kilometre travelled by motorists. We also have other indirect user charges—such as myriad vehicle registration fees and motor vehicle stamp duties on new vehicles and transfers of ownership. Australia, therefore, currently has a two-part cost recovery scheme for road use involving both federal and state levels of government, with 'fixed' charges represented by vehicle registration requirements plus a 'marginal' charge through the fuel excise levy, which is tied to usage. One of the main problems today-and a principal concern for policymakers-is that the marginal charge does not always reflect social marginal costs. Many argue, for example, that charges are too low on congested roads and too high on uncongested roads.

\section{Marginal cost and average cost pricing}

Most of the economic issues associated with pricing are not new. Figure 6.1 shows an idealised example of an infrastructure project. Average costs (AC) of supply, which include fixed, upfront construction costs, tend to be higher than the marginal cost (MC).

In Figure 6.1, when marginal benefits (MB) (at the point $\mathrm{Q}^{*}$ ) equal marginal costs $(\mathrm{MC})$, we have an efficient level of output (but note the exception discussed below). The problem is that if the facility has fixed costs (AC), the public (or private) entity that is going to run such facilities will run at a loss under marginal cost pricing, since average costs exceed marginal costs. The rectangle between $\mathrm{D}-\mathrm{AC}-\mathrm{MC}$ represents the fact that this entity is running at a loss, and that loss has to be subsidised from somewhere. This is a well-known, fundamental issue with marginal 
cost pricing: even though it generally could be implemented, it is not necessarily 'incentive compatible' in that it will not align usage with average costs or allow the owner to break even.

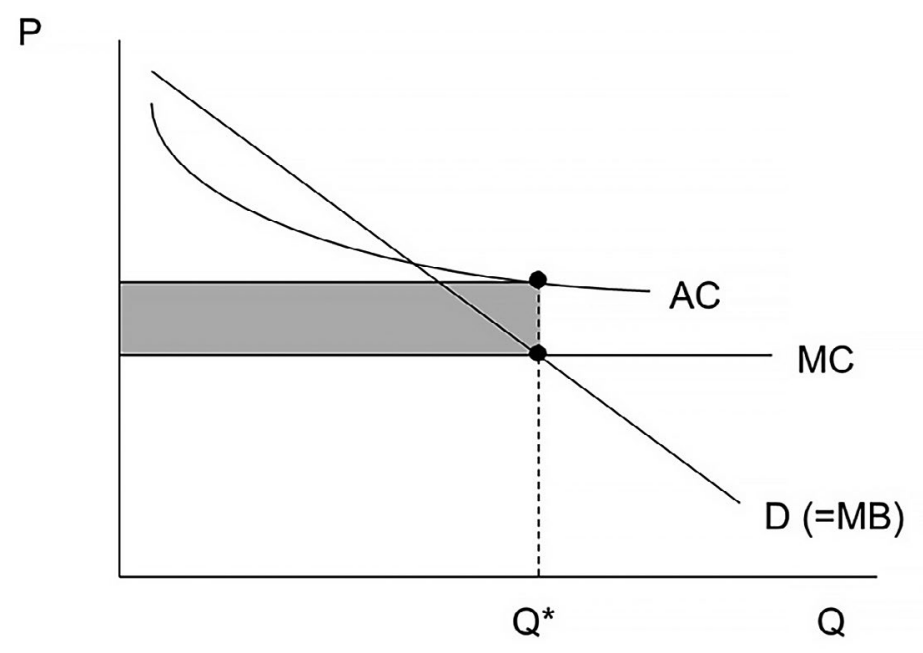

Figure 6.1 Marginal cost pricing

Source: Author's work.

Another issue in relation to marginal cost pricing is the argument put forward by Ronald Coase (1946). Suppose that government provides a good or service and commits to price it at a marginal cost. If fixed costs are high—so that average costs remain high—-then under the marginal cost pricing rule we could achieve some 'optimal' level of usage at $\mathrm{Q}^{*}$. At this point, marginal benefits appear to equal marginal costs, but what could in fact occur is that the project is socially wasteful (see Figure 6.2). The reason is the fixed costs are just too high. So, in this situation, it is straightforward to design an infrastructure pricing scheme for which the price equals marginal costs, but this is a project that should not go ahead at all. In summary, we can get people to reveal their demand curve by having some sort of pricing scheme where price equals the marginal cost, but that does not necessarily have anything to do with whether the project is a good idea in the first place. In cases like this, Coase proposed the idea of a two-part tariff, with an access fee to cover fixed costs and a price per unit equal to marginal costs. 


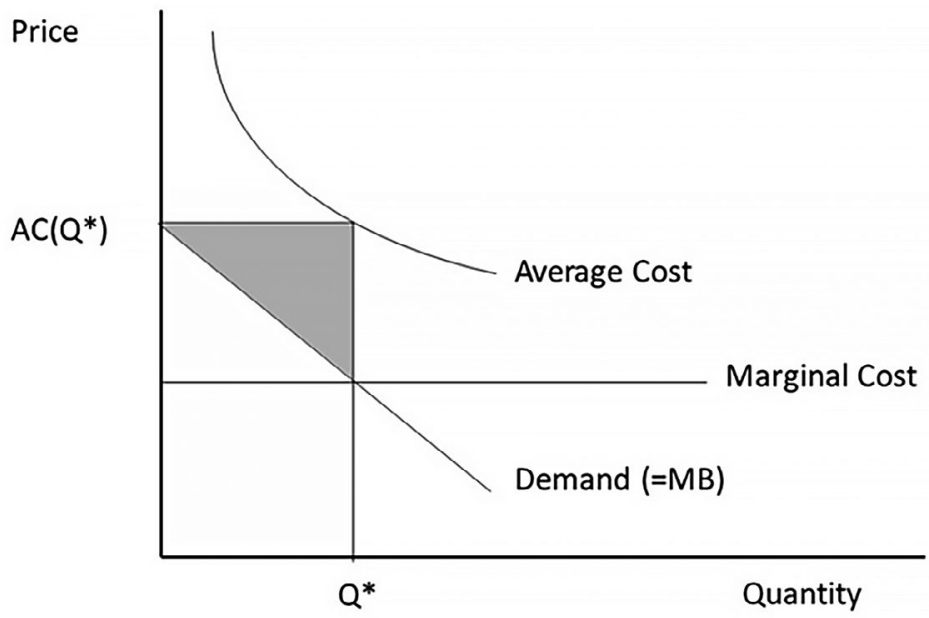

Figure 6.2 Marginal cost pricing may produce a socially wasteful outcome Source: Author's work.

Another alternative is average cost pricing (see Figure 6.3). The issue here is that we immediately get an efficiency loss: the project breaks even, but there is a deadweight loss triangle because price exceeds marginal cost. This is a second-best outcome. We may be willing to put up with that, but it is not a first-best solution.

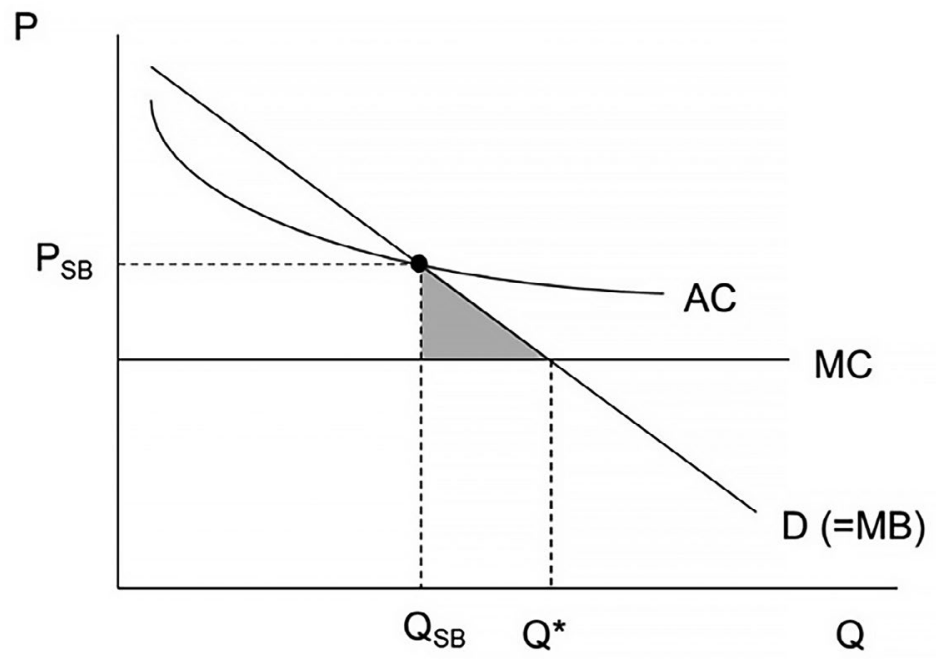

Figure 6.3 Average cost pricing

Source: Author's work. 
A practical issue with average cost pricing concerns implementation. If the average cost curve cuts the demand curve at two or more points, we have to decide which average cost will actually be charged. Figure 6.4 shows this situation. At the point $\left(\mathrm{P}_{0}, \mathrm{Q}_{0}\right)$, price equals average cost, so the project breaks even. But this is not a second-best point, because the deadweight loss is higher than it would be at the other point in the diagram where the average cost curve cuts the demand curve. So an average cost pricing rule provides only a partial answer in this situation.

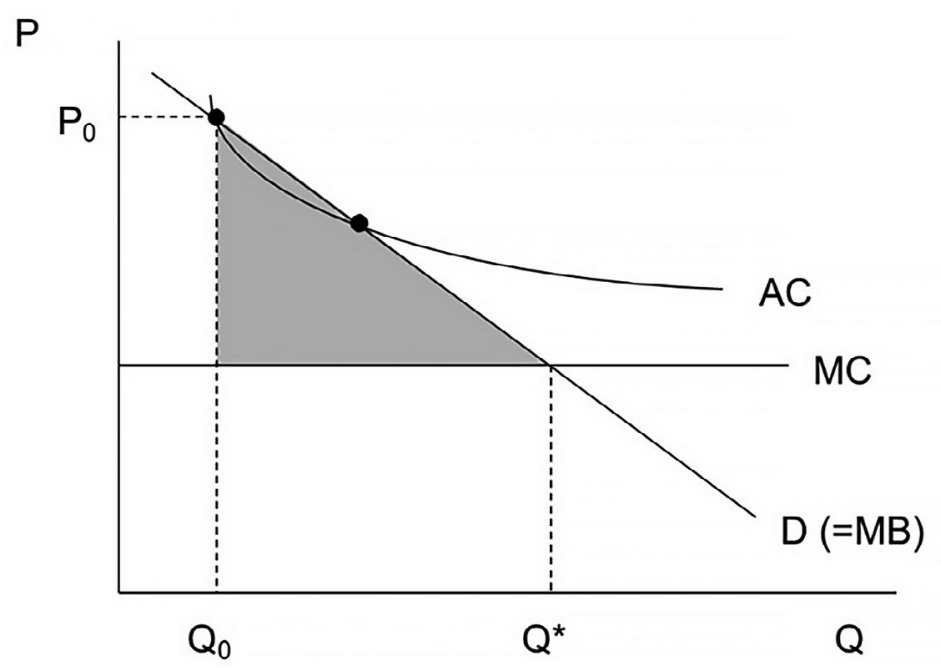

Figure 6.4 Average cost pricing: Which average cost?

Source: Author's work.

A final difficulty with average cost pricing is that it may not even be feasible-in the following sense. In Figure 6.5, the area under the demand curve far outweighs the total cost of the project, so this is a project that is socially beneficial. But there is no average cost price that exists here that will allow the project to break even. The basic lesson is that, although these pricing rules - marginal cost and average cost pricing-are simple in theory, they are likely to face a range of difficulties in practice. 


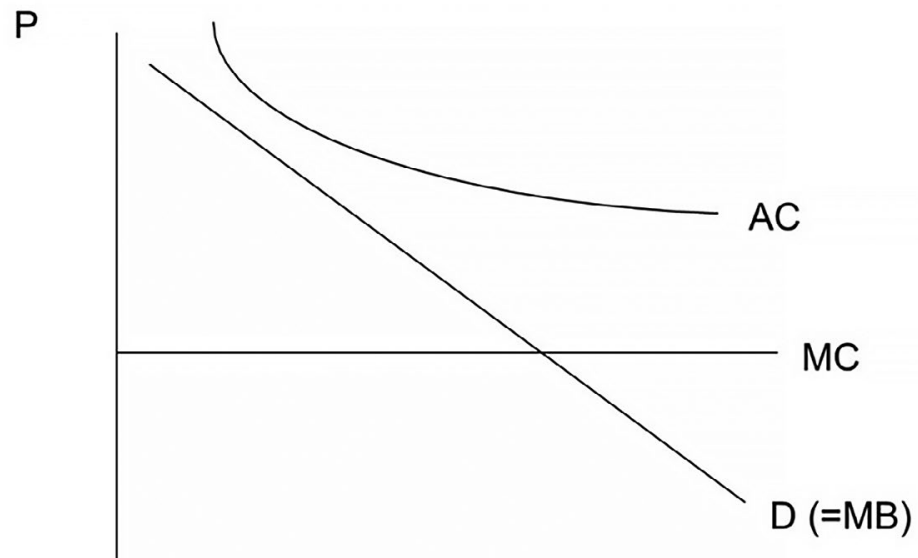

Q

Figure 6.5 Average cost pricing: Existence?

Source: Author's work.

\section{Congestion pricing}

Policymakers often face a range of other issues in relation to road users. One well-known issue is the concentrated times that consumers use the infrastructure. This raises issues around congestion pricing. When there is high road use, a road becomes an example of an 'open access' or 'common pool' resource: it is non-excludable, but rival in consumption. Congestion is a classic example of a 'negative externality', and we get non-price rationing in the form of queuing and long delays. This likely represents an efficiency loss, as some people with higher-value uses face delays and the social cost of lost time, and the congestion may have even completely excluded some high-value users.

The idea of congestion pricing is that it tries to produce a better allocation of that road space to high-value users. Roads with high-value users can gain, but those with low value can potentially lose. Figure 6.6 illustrates a situation in which we have a classic example of a congestion externality: at the margin, social costs exceed private costs. The optimal outcome here is to set a Pigouvian tax or charge that reflects the 'negative externality' at the optimum, which is at $\mathrm{Q}^{*}$ in Figure 6.6. In the absence of a charge, we get a welfare loss of $\mathrm{G}$, which is the sum of the excess of social costs at the margin over social benefits at the margin from driving. 
Optimal congestion pricing operates as follows. At point $\mathrm{Q}^{* *}$, social marginal benefits equal social marginal costs. The optimal charge is the gap between marginal benefits and costs at this point, and is indicated on the vertical axis on the left-hand side of the figure. When this charge is introduced, there are some people who will be 'tolled off (lying between $\mathrm{Q}^{*}$ and $\mathrm{Q}^{* *}$ ), and they will choose to no longer drive, reducing overall demand. Naturally, they are personally going to lose out, as shown in area $\mathrm{F}$ - the excess of their private benefits over the costs they faced before the charge was introduced.

On the other hand, road users who continue to use the road will have quicker commute times, because now their costs of travelling are lower by $C$ plus $D$. But notice that their travel cost, plus the monetary cost (A plus B), is actually higher than the total travel costs they initially faced.

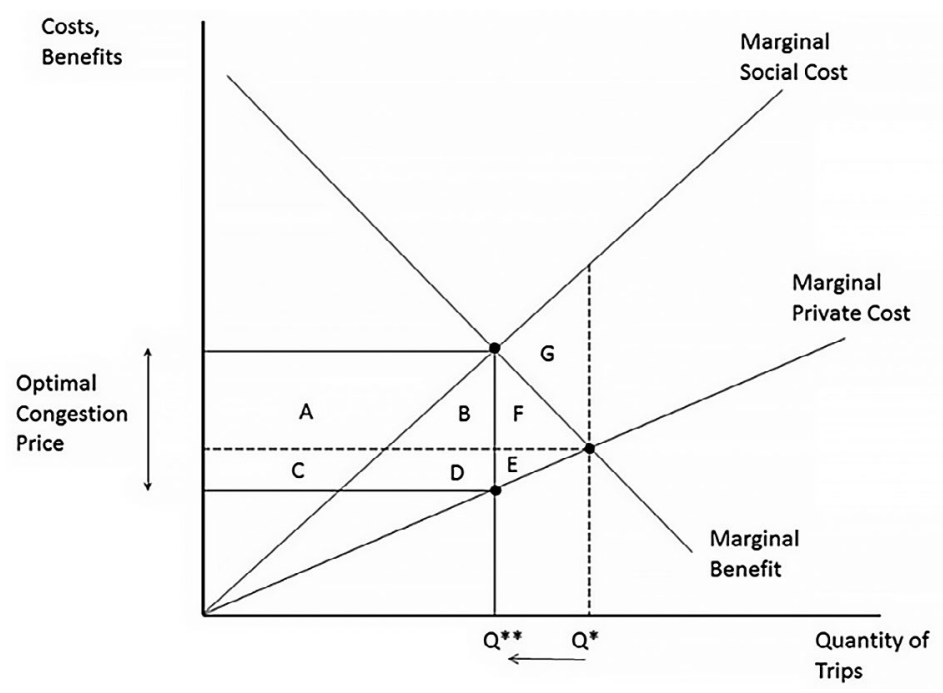

Figure 6.6 Congestion pricing

Source: Author's work.

This brings us to one of the major potential problems with congestion road pricing - and one that could explain why it has not taken off in Australia: at the optimal charge, people who continue to drive will be worse off. They save on their travel time, but the optimal charge increases their overall costs of travel. Society as a whole gains, because the government gains revenue from the toll. The net social gain is $G$ (we have eliminated the original deadweight loss). Equivalently, the net gain is $\mathrm{C}$ plus $\mathrm{D}$ minus F, which is equivalent to the area $G$. 
In summary, the issue governments face is that drivers who are going to be tolled will in fact face a charge that - from an individually rational point of view-they do not want to pay. Simply put, when we levy the optimal toll, people are going to feel it in their hip pocket and will feel directly worse off-even though there is less congestion. So, although cultural or historical factors may be important for explaining why tolls have been unpopular in Australia, economics provides us with an alternative explanation: drivers may be worse off, even though congestion falls and society as a whole is better off.

This suggests that while it is always possible to think in the abstract about an efficient congestion pricing regime, implementing such a charge is going to be very difficult politically. Governments would need to persuade people that this is a good idea, either by using the revenue wisely or by carefully hypothecating it and using it as a sort of persuasive device (which may have its own efficiency costs).

\section{Other practical difficulties with congestion pricing}

\section{Measuring benefits}

There is a range of other practical difficulties that governments face if they are trying to convince people that congestion pricing is a good idea. In assessing any congestion pricing scheme, it is important to take care that we are counting benefits properly. Measurements of the total costs of congestion abound, but from an economic point of view they are not particularly interesting. What should ultimately be of interest to policymakers are the congestion costs that are avoided if an optimal pricing scheme is implemented. Some amount of congestion is efficient; it would not be optimal to have no congestion at all. The upper bound of the net benefit of congestion charging is the area $G$ in Figure 6.6 (and it really is an upper bound, because congestion pricing schemes can be costly to run). Importantly, notwithstanding the total costs of congestion, if a significant portion of the revenue from congestion pricing is spent on collection costs, or is wasted, this could outweigh the benefits, $\mathrm{G}$, and the pricing scheme could actually make society worse off. 
On the other hand, there are other benefits to consider. In addition to savings in journey times for commuters, there are reductions in fuel use and pollution emissions. Accident externalities and their associated costs may also fall, although this is by no means certain; a reduction in congestion may induce commuters to drive faster. In the long run, society may also benefit from a better allocation of road space.

\section{Spillover effects}

Another well-known difficulty is the potential for charging on one road to have spillover effects on to untolled roads. Introducing a charge on one road may simply divert traffic and worsen congestion on other roads. Any real-world assessment of congestion pricing ought to account for these costs as well.
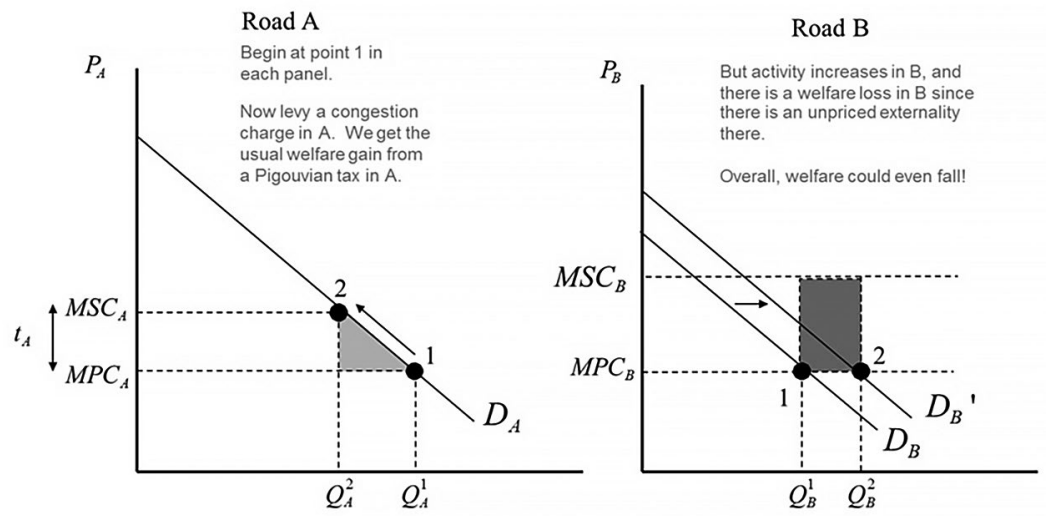

Figure 6.7 Example 1: Incomplete congestion charging

Source: Author's work.

Figure 6.7 illustrates the theory, but there are many examples of this in practical policymaking. Alcohol taxation-specifically, the recent 'alcopops tax' (introduced in 2008) — is a good case in point. The alcopops tax was supposedly designed as a kind of Pigouvian tax on certain types of alcoholic beverages. The practical problem was that it was easy to substitute alcopops for other types of alcoholic beverages with their own social costs. If those costs have not been priced correctly, there will be a negative welfare effect from switching to those other things that could outweigh the positive effect of reduced alcopop consumption. The same phenomenon is possible with higher tobacco taxation, where the effect 
of reducing tobacco use might be that consumers switch to other socially undesirable things (such as hard drugs or other illegal substances), which themselves are not taxed in the optimum Pigouvian way.

Other examples abound. With congestion pricing, the concern is that while we may be able to reduce congestion on one road, this may lead to people doing 'rat runs'-using other roads-and simply shifting the congestion into other areas. This then reduces the welfare gains identified in Figure 6.5, and we could end up with a negative overall welfare effect if these other distortions are large enough.

Another possible difficulty with congestion charges is that, while there will be fewer people choosing to drive, they may not have alternative modes of transport (such as convenient, easily accessible, inexpensive public transport). In response to a congestion charge, individuals may decide to not work at all. This would reduce labour supply, which is already distorted by other taxes such as income taxes, payroll taxes and the goods and services tax (GST). So there could be a welfare loss in the labour market that needs to be accounted for (see Figure 6.8).
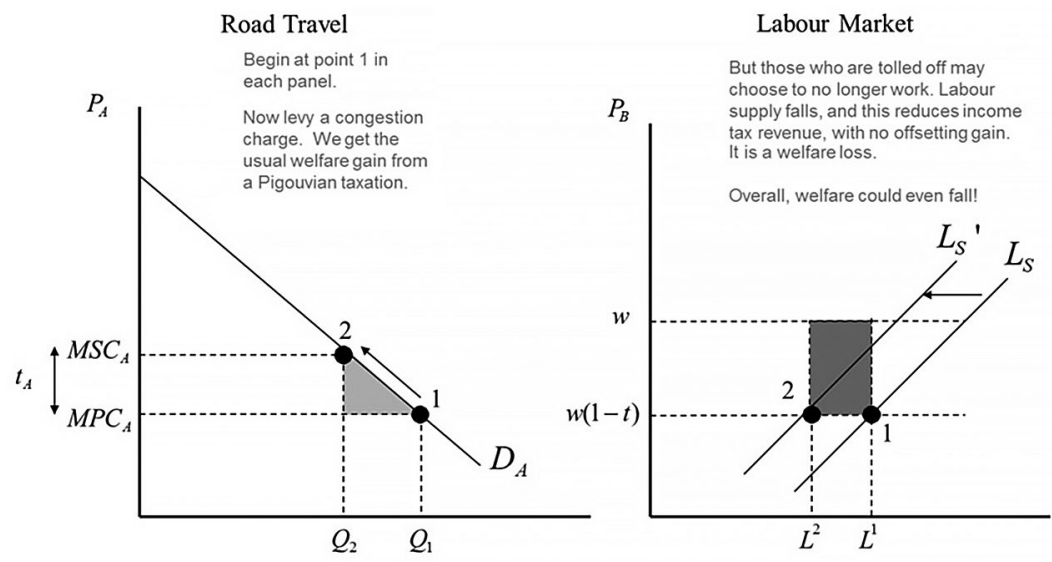

Figure 6.8 Example 2: Interaction with labour taxes

Source: Author's work.

These spillover effects may seem like esoteric points, but in the real world they are very important. The essential point is that we are likely to produce unwanted spillover effects in markets that are already distorted and, if these effects are large enough, we need to count them in any costbenefit analysis of road pricing. 


\section{Forecasting demand}

Another practical difficulty in regards to road pricing in Australia is forecasting performance. The simple models examined above assumed that policymakers knew what traffic demand looked like and how it would respond to the introduction of a toll. If the traffic forecast turns out to be wrong, additional costs can ensue. Suppose, for example, that the government has implemented a toll in such a way as to balance out expected marginal benefits and expected marginal costs. Figure 6.9 shows what that toll might look like. If, however, actual demand turns out to be lower than expected, from an efficiency point of view, the imposed toll should have been lower. In Figure 6.9, the toll is far too high, producing a social loss because the traffic forecast was wrong.

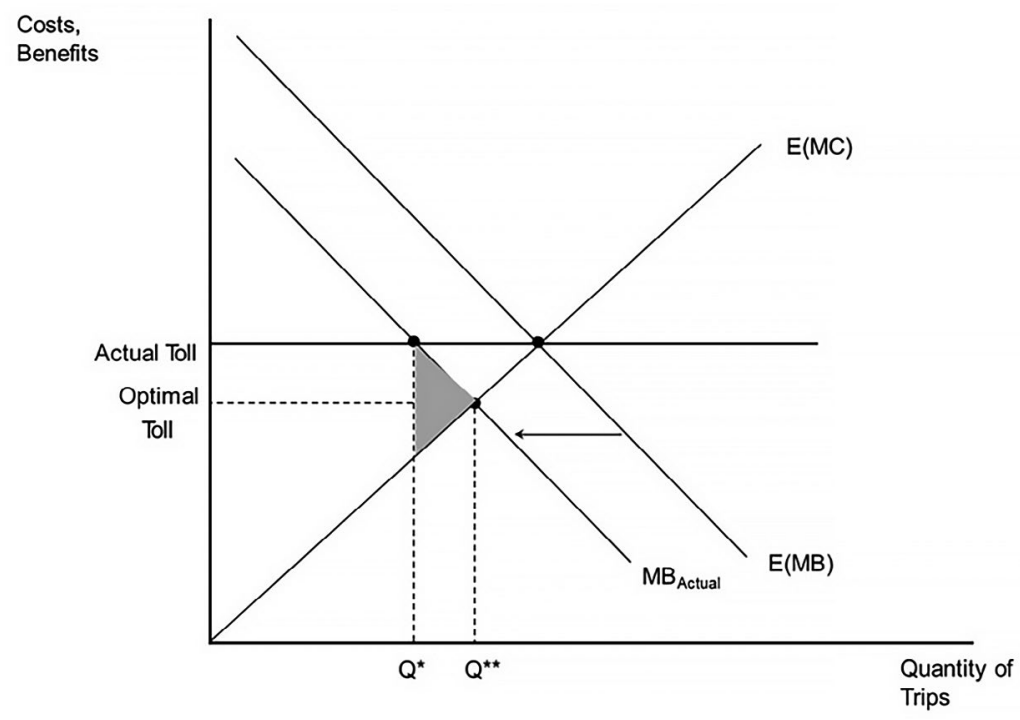

Figure 6.9 Social costs of poor traffic demand forecasting performance Source: Author's work.

This has been a genuine problem in Australia. Table 6.1, which was put together by Robert Bianchi at Griffith University, shows the performance of toll roads in Australia over the past decade or so. In most cases, it has not been good. Li and Hensher (2010) point out that demand forecast errors in Australia have, on average, been minus 45 per cent-actual demand tends to be 45 per cent lower than predicted. The cost of overforecasting demand is one that must be taken into account when we are thinking about the benefits and costs of various policies. 
Table 6.1 Average toll road traffic performance since 2000

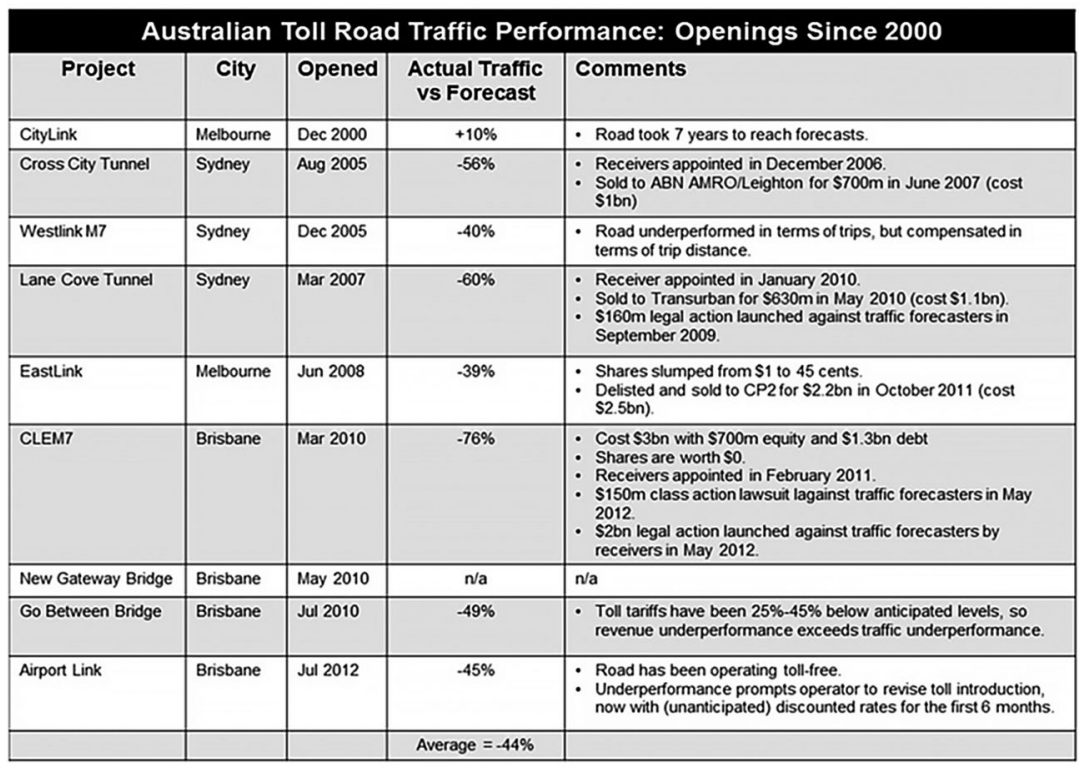

Source: Robert Bianchi.

\section{Congestion charging as monopoly pricing}

Another issue that could arise in practice is if congestion charging is used purely as a revenue-raising device. Governments are often in positions where they are pure monopoly providers of roads and can therefore charge a price (or allow a private provider to charge a price) that maximises profits, rather than the optimal congestion charge. In Figure 6.10, the price charged is relatively high, but the welfare loss caused by the monopoly pricing here is shown in the shaded area to the left. The welfare gain that could have been obtained is the shaded area to the right. It is not clear which of those triangles is larger here; if governments are going to use road pricing just as a revenue-raising device and act like a pure monopoly, they could end up making things worse. 


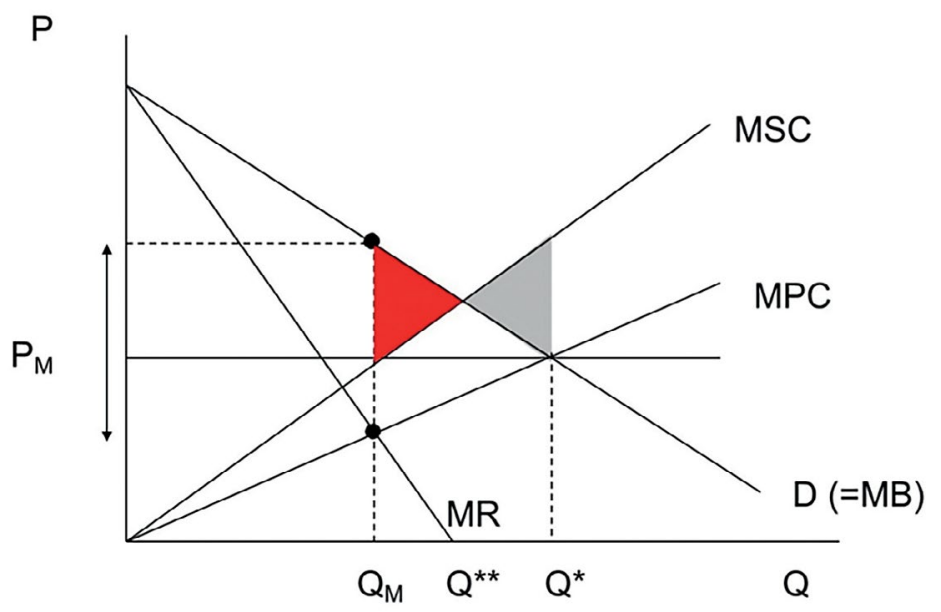

Figure 6.10 Congestion charging as a pure revenue-raising device Source: Author's work.

\section{Conclusion: The importance of rigorous cost-benefit analysis}

All of this points to the need for careful cost-benefit analysis of pricing schemes and road charges, because it is by no means a foregone conclusion that pricing is always going to provide net benefits. As this chapter has demonstrated, in theory, we can think of cases where pricing schemes are a good idea, but it is just as easy to think of cases where they are not.

One of the main reasons for undertaking a rigorous cost-benefit analysis is to reduce or eliminate theoretical ambiguities and deal with two types of errors:

- There is a policy that is beneficial, but is not adopted because the initial assessment is that it is not beneficial—and no cost-benefit analysis is conducted to demonstrate that the initial perception is incorrect.

- A bad project goes ahead (but would not have proceeded if a costbenefit analysis had been undertaken).

A good cost-benefit analysis will not always give the perfect answer or completely eliminate uncertainties, but it will tend to reduce the probabilities of making these kinds of policy errors. 
I conclude with a word of caution from a well-known infrastructure example that illustrates what can happen in public policy when policymakers do not use cost-benefit analyses appropriately: the National Broadband Network. No cost-benefit analysis of the initial rollout of fibre-optic cable was undertaken, and costs and timing have subsequently blown out. Ergas and Robson (2009) undertook such an analysis and found that the project's costs would exceed its benefits by somewhere between $\$ 40$ billion and $\$ 20$ billion, depending on the discount rate used. A proper cost-benefit analysis would have identified many of the subsequent construction and cost risks.

\section{References}

Coase, R. H. (1946). The marginal cost controversy. Economica 13(51): 169-82.

Ergas, H. and Robson, A. R. W. (2009). The social losses from inefficient infrastructure projects: Recent Australian experience. 17-18 August. Available from: www.academia.edu/8569365/THE_SOCIAL_LOSSES_ FROM_INEFFICIENT_INFRASTRUCTURE_PROJECTS_RECENT_ AUSTRALIAN_EXPERIENCE

Li, Z. and Hensher, D. A. (2010). Toll roads in Australia: An overview of characteristics and accuracy of demand forecasts. Transport Reviews 30(5): 541-69. doi.org/10.1080/01441640903211173 
This text is taken from Road Pricing and Provision: Changed Traffic Conditions Ahead, edited by Michael de Percy and John Wanna, published 2018 by ANU Press, The Australian National University, Canberra, Australia.

doi.org/10.22459/RPP.07.2018.06 